\title{
Study on the Development and Incentive Mechanism for College Teaching Management Staff under New Situation
}

\author{
Lili Liu ${ }^{1, a^{*}}$ and Xuehong Chang ${ }^{1, b}$, \\ ( ${ }^{1}$ Jilin Agricultural University, Changchun , 130118, China) \\ a79856004@qq.com , b66414623@qq.com
}

Keywords: Colleges; Teaching Management Staff; Incentives; Problems; Policies

\begin{abstract}
Over the past decade, the colleges in China have undergone tremendous changes, and the scale is also constantly expanding. Colleges are the base to cultivate talents for the future, which play a pivotal role in making our country stronger. The development of colleges does not only require the coordination and cooperation between teachers and students, but also the bond function played by teaching management personnel. Therefore, we have to be fully aware of the importance of teaching management staff. This paper is going to start from the perspective of incentive and incentive mechanism, which will also elaborates the present situation and the existing problems of the incentive mechanism in colleges so as to make some references. Based on this, we are able to further improve the management skill and create a better academic atmosphere.
\end{abstract}

\section{Introduction}

In this knowledge economy era, education is the foundation of the country. Therefore, colleges shoulder heavy responsibilities in cultivating talents. In order to operate efficiently and smoothly, it is far away from enough to only depend on the coordination between students and teachers. College teaching management personnel act as an important link for students and teachers and also play an important role in teaching management. Therefore, no matter the government, the society or individuals should be fully aware of the teaching management team and the important role the teaching management personnel play in smoothly operating colleges. Thus, relative document called Teaching Assessment Plan of Undergraduate Education (hereinafter referred to as Plan) has been published to make a clear definition on the college teaching management team and at the same time point out that the management team is an important guarantee for qualified education. Meanwhile, it also helps to develop the teaching management team, and highlights their importance for attention.

As far as the current situation is concerned, a glittering array of colleges have begun to focus on the recruitment of teaching management staff and also improved the recruitment threshold, which helps to create a new situation. However, there are still lots of problems, including no passion, negative improvement and no career plan etc. Therefore, concerning the above problems, the key is to find out how to solve the problems. This paper is going to discuss some effective incentive schemes to improve the passion and efficiency of various teaching management personnel so as to make the teaching management more orderly and efficient.

\section{Incentives and Related Mechanism}

No matter in colleges or companies, the crucial factor in human resource management is incentive. That is to say, excellent management cannot be separated from incentives. So what is the so-called incentive? Conceptually, incentives can be used to effectively encourage individuals to realize the target with high motivation. Essentially, it can be deemed as an external effective stimulus to trigger inner motivation and its purpose is to dig into the potential and creative thinking of people, fully play their initiative to complete the goal. So what is the incentive mechanism? By definition, it refers to a series of regulations, systems, policies or measures adopted inside the company, aiming to stimulate employee's enthusiasm, standardize the work behavior, guide the direction of work etc. 
which is considered as an important means to bring people's enthusiasm into play and coordinate the organization operation.

Although we have introduced incentive and incentive mechanism, but we don't know their relation and their connection as well as difference is vague. Incentive is to trigger and encourage people so as to fully play people's initiative, enthusiasm and creation. Incentive mechanism refers to a series of complete operation system made up by diverse means. Incentive refers to motivation and target while incentive mechanism refers to system and means. Incentive mechanism can be continually adjusted and improved based on the targets so as to be adapted to new requirement. A good incentive mechanism should be equipped with the following characteristics: First, the incentive content should focus on the spiritual level rather than material level; second, incentive forms should pay more attention to individuals instead of organization level; third, incentive targets should lay stress on the result; fourth, incentive time should emphasize on the previous stage.

\section{Analysis on the Current Condition of Incentive Mechanism for College Teaching Personnel}

Lack of Identity and Achievement. With the increasing emphasis on education the investment on colleges is soaring and therefore the scale and quantity of colleges have also increased a lot. Among faculties in colleges, the proportion of teaching management personnel has also increased while colleges do not pay much attention on them but teachers and students. According to relative researches, the work carried out by teaching management personnel is repeated and does not require a lot of technique from the perspective of teachers and students. Based on this, we can obviously conclude that most of college teaching personnel are not respected. As a result, they do not have a sense of identity. In addition, colleges always set a high recruitment threshold, most of the jobs require a master degree or even doctor degree. So, when those highly educated people work a lot but are not respected, a negative sense will emerge and they will feel confused about their future.

Absence of Focus on the Career Plan of College Teaching Management Personnel. In addition to students, only professional teachers can be paid attention to. Concerning the title evaluation and career development, most of the colleges have clear rules for promotion, which definitely has brought about pressure but also clear career development suggestions. However, when we look at college teaching management personnel, they do not have a clear career plan because they are not paid much attention to. According to traditional philosophies, those teaching management personnel act the role of assistance and service, and there are no proper polices to satisfy their needs.

The Evaluation System for College Management Personnel is not Perfect and Comprehensive. Almost all colleges adopt single assessment methods to evaluate teaching management personnel, which mainly evaluate their morality, ability and diligence along with work report. However, this kind of assessment cannot comprehensively show their performance. Meanwhile, every assessment has a ratio setting and those who are super excellent and unqualified occupy the least ration and most of them are evaluated as qualified. Obviously, we can see the disadvantage of this assessment method, which cannot encourage them to carry out work but make them be tired of work.

The Salary \& Welfare System as Well as the Reward and Punishment System Is not Clear. From the above analysis we can know that most of the teaching management personnel are evaluated as qualified, and therefore there is no big difference in terms of salary and welfare. At the same time, teaching management personnel are considered with the role of assistance and service. So, they don't have many opportunities to apply for projects and honor. As a result, this current condition will make them become tired of work and negative about work. Further, they shall lose the passion and will not take the initiative to innovate and compete.

\section{Incentive Strategy Suggestions for College Teaching Management Personnel}

Pay More Attention to College Teaching Management Personnel and Encourage them to Take the Initiative. To begin with, we can conclude a common cause for their lack of enthusiasm is that 
college teaching management personnel are not paid much attention to. Therefore, colleges should highlight the role those college teaching management personnel played and help students and teachers to understand that they are mutually constructed. Thus, the will realize that a scientific as well as effective teaching management will be conducive to the smooth development of all kind of work. As a result, they will identify that those teaching management personnel are very important while they will also have a sense of identity.

At the same time, all levels of leaders should fully highlight the role those teaching management personnel in making a college successful and they should be provided with a fair and just platform for giving their voice and developing themselves, which will also further improve their autonomy and initiative. Moreover, their work should be highly appreciated to help create a sense of identity and accomplishment. To be concrete, along with the development of information technology, we can adopt QQ group, Wechat group etc. to strengthen the communication and feedback. Their work is directly related to the proper operation of the faculty team. For example, if a teaching management personnel can timely deal with the exam schedule, exam evaluation etc, it will greatly help with the smooth process of teaching. Therefore, their work and themselves should be respected. Furthermore, those teaching management personnel and teachers exist side by side and play a part together. So, teaching management personnel should also establish the idea to serve teaching and serve teachers so as to make the smooth operation of a school. The development of time puts forward higher requirement on college education and full-time master degree education as well as some outstanding engineering projects emerge as time required, which add some work opportunities but also more work. College teachers should fully be aware of this and positively coordinate with various departments to help with the smooth development and improve together.

Establish Normalized Teaching Management Personnel Training System. According to the current condition, lots of colleges have carried out some training for teaching management personnel as needed. However, it is not enough because not many teaching management personnel are involved and some colleges do not have normalized training system. This current condition makes those teaching management personnel involve in daily work and they do not have opportunities to improve their professional knowledge which also limited their development.

Concerning this condition, colleges should pay a lot of attention to and start to establish normalized training system, which should not only cover the topics of business content but also their skills, management training as well as management experience communication with foreign colleges. Meanwhile, we should also include junior officers so as to widely and comprehensively improve them and satisfy their needs.

Clear the Promotion System for Teaching Management Personnel, Open up Their Development Channels. VictorH. Vroom, a famous American psychologist and behavior scientist proposed the Expectancy theo-ry to bring people's enthusiasm into play, the formula is as follows: excitement=expectation * core potency, which clear that the function of target to individuals is determined based on people's estimate of realizing the targets and its value. That is to say, the more possible that an individual think he will accomplish something, the greater the value will be and he will be motivated and encouraged greatly. Therefore, colleges should provide sufficient development and promotion space for teaching management personnel. To be more specific, we can take the following suggestions: we can set development layers and those who shine out will obviously have more opportunities to get promoted; expand the work possibility; create access to title appraisement for them etc.

Establish a Scientific Salary \& Welfare System as Well as Reward \& Punishment System. We have analyzed the problem that there is no big difference of the salary \& welfare system as well as reward \& punishment system, and we should make a difference to fully encourage teaching management personnel to improve themselves. What's more, the reward \& punishment system should be subdivided. They should not only get promoted based on morality, ability, diligence and work report but also a comprehensive observation based on their job characteristics. Meanwhile, for those who are very outstanding in terms of innovation and business, we should provide them with more opportunities of project application and capital support so as to let them know that their 
excellent job is highly appreciated to satisfy their development. The fact is it is very difficult to quantify their work and a flexible plan should be carried out so as to select and award excellent ones based on diverse means. We should also create more opportunities and platforms so as to let them participate in scientific research and teaching project to stimulate their enthusiasm to work, create and innovate.

\section{Conclusion}

All in all, we should fully be aware of the important role college teaching management personnel played among faculties and we should relate them with the higher education targets. It will be of significant importance if we can introduce those teaching management personnel with higher business ability and management ability into work. Hence, college teaching management personnel should be paid attention to and we should provide more opportunities to help them fully play their talents, which also plays a pivotal role in establishing a scientific and perfect incentive schemes for them.

\section{Acknowledgments}

2015 annual Jilin Education Department vocational education and adult education reform research project. Number: 2015ZCY174

\section{References}

[1] Y.Zhang: Modern Economic Information, (2012 ) No.9.p.70-71.(In Chinese)

[2] X.Y.Zhuang: Public Management ( Fudan University Press , 2012.)

[3] N.Liu:Higher Education Forum, (2015),p.155 156. (In Chinese)

[4] B.H.Liu:LCreative Education, (2015),p. 156. (In Chinese)

[5] B.Wu:School Management, (2015),p.236. (In Chinese)

[6] D.T.Wei: Journal of Guangdong Polytechnic Normal University ( Natural Science), (2015 ) No.5.p.136-140.(In Chinese)

[7] G.H.Guo: Liaoning Economy, (2015 ) No.5.p.86-87.(In Chinese)

[8] X.Y.Yue: Journal of Changchun Education Institute, (2015 ) No.3.p.110-111.(In Chinese)

[9] L.B.Zhao and Y.X.Zhu: Administrative Tribune, (2012 ) No.4.p.89-92.(In Chinese)

[10] Special Topic Research Department of Reform Magazine: Reform, (2012 ) No.4.p.5-15.(In Chinese)

[11] X.D.Wang and J.Y.Liu: Journal of Educational Institute of Jilin Province, (2014 ) No.2.p.2728.(In Chinese)

[12] S.Y.Pei:The Improvement of Human Resource Management in Public Sectors of China.(Yan'an University, 2013).

[13] L.Y.Zou: Thoughts on Reform Positioning in Public Institutions .(Minzu University of China, 2013). 